\title{
Review Article \\ Dietary Strategies for Better Utilization of Aquafeeds in Tilapia Farming
}

\author{
Thandile T. Gule $\mathbb{D D}^{1}$ and Akewake Geremew $\mathbb{D}^{2}$ \\ ${ }^{1}$ African Centre of Excellence for Water Management, Addis Ababa University, P.O. Box 1176, Addis Ababa, Ethiopia \\ ${ }^{2}$ Addis Ababa University, College of Natural and Computer Sciences, Department of Zoological Sciences, P.O. Box 1176, \\ Addis Ababa, Ethiopia
}

Correspondence should be addressed to Thandile T. Gule; thandile.gule@aau.edu.et

Received 23 October 2021; Accepted 9 January 2022; Published 31 January 2022

Academic Editor: Ayşegül Kubilay

Copyright (C) 2022 Thandile T. Gule and Akewake Geremew. This is an open access article distributed under the Creative Commons Attribution License, which permits unrestricted use, distribution, and reproduction in any medium, provided the original work is properly cited.

\begin{abstract}
Feed management practices significantly impact the production performance of tilapia (Oreochromis species) culture economically; hence, adopting appropriate feed management strategies is vital to maximize returns. The advancement in aquaculture has also allowed an advancement in the development formulated feeds to supplement or replace natural feeds. Farmers are now able to prepare their own fish feeds from locally available ingredients. Hence, feed ingredient evaluation is crucial for better development of appropriate diets for different aquaculture species as well as nutritional research. Therefore, this review used secondary data to evaluate the different strategies employed for better utilization of nutrients in feed by providing a discussion of functional feed additives used in aquafeeds such as the addition of enzymes, pre/probiotics, feeding stimulants, and use of hormones. Supplementation of diet with xynalase and phytase enzymes $(P<0.001)$ and probiotics $(P<0.05)$ improved growth $(\mathrm{g} / \mathrm{d})$ and FCR when applied individually. The combination of enzymes and probiotics showed an interaction effect $(P<0.05)$ on growth and FCR. A detailed discussion of feed ingredient processing strategies like fermentation, heat treatment, germination, and other biological methods meant to improve the nutritional quality of the feed and minimize antinutritional factors is provided. Furthermore, information on how genetic selection is being used to enhance feed utilization in tilapia fish is provided. The food conversion efficiency was found to be significantly higher $(P<0.05)$ in transgenic tilapia compared to the nontransgenic red tilapia fish with average weight \pm SD of $384 \pm 158 \mathrm{~g}$ and $314 \pm 101$ for transgenic fish and red tilapia, respectively, after 275 days of culture. The review further outlines the feed formulation challenges, and research gaps in tilapia nutrition. It was noted that proper feeding management strategies are very critical for the sustainability of tilapia aquaculture. In conclusion, dietary sources for tilapia are slowly shifting to plant-based products. However, these come with a lot of antinutritional factors and digestibility problems; hence, the right feeding strategies have to be employed to enable efficient nutrient utilization. The review discovered that there are a lot of strategies which employed research gaps in tilapia nutrition, especially on nutrient utilization of feed and feed formulation.
\end{abstract}

\section{Introduction}

Tilapia are omnivorous fishes from the cichlid family native to Africa and have been widely introduced all over the world either accidentally or deliberately [1]. Tilapia is the second most commercially farmed fish group after carp (Cyprinus species) under intensive aquaculture in many developing countries where it acts as an important protein food source [2]. Of all these tilapia species, Nile tilapia (Oreochromis niloticus) is the most commonly farmed with over 4.5 million metrictons \pm SD of fishes produced per year in 2018 (Figure 1) [3] and produced in more than 100 countries [2].

Tilapia farming largely involves feed as one of the major operating costs; therefore, the need for assessing the nutritional requirements, feeding management strategies, and nutrient utilization strategies is essential to ensure sustainable production and scalability in tilapia farming. Moreover, 


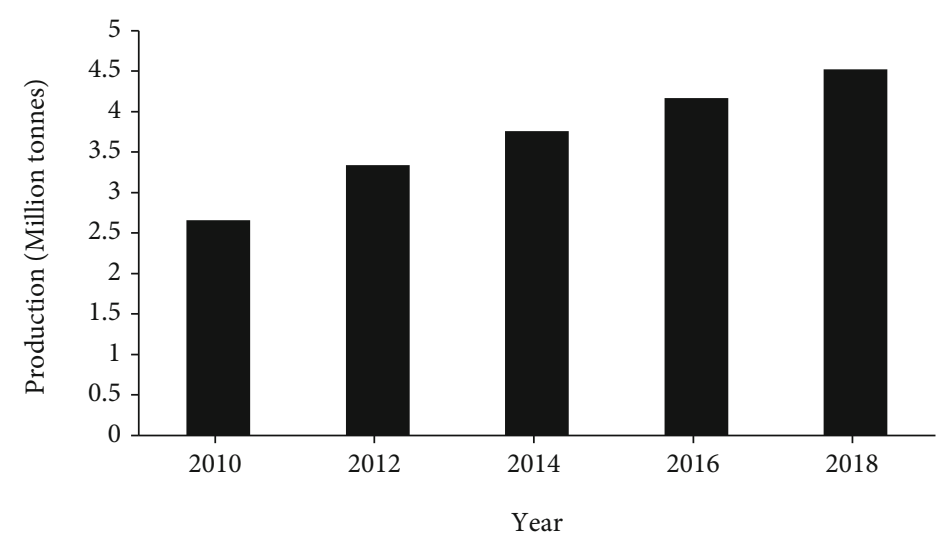

FIGURE 1: Total contribution of Nile tilapia to global tilapia production from 2010 to 2018 . Black represents Nile tilapia, and grey represents other tilapia species [3].

the increase in tilapia production means that more efficient and productive feeding strategies need to be developed. At this stage, the economic viability of formulating the feed needs to be taken into consideration to ensure a positive net return [4]. This factor is one of the determinants of the long-term adoptability of every feeding strategy. Another important factor is the nutrient utilization efficiency of the feed. This is because not all nutrients that are present in the feed are assimilated and converted to useful energy, but some are lost in the system. If only a small proportion of the total nutrients in a feed is being assimilated and retained by the fish, the system becomes nutrient inefficient, and a lot of waste is generated instead. This is both economically unviable and a concern to the environment and water quality. Therefore, it is important that every feeding strategy employed is nutritionally efficient to minimize feed wastage and deterioration of water quality $[5,6]$. This can be done by assessing information on nutrient utilization to estimate the efficiency as this varies upon the fish species and the farming system [7]. With this in light, it is essential that the nutrient utilization and economic viability of different tilapia dietary strategies are kept in check.

There has been great advancement in fish nutrition over the years, accompanied by the development of specific feed formulations, with new, balanced commercial speciesspecific diets that promote optimal growth and highquality healthy fish production. However, nutrient requirements and improved feeding strategies and their efficiency are not fully understood worldwide, especially in the African continent. Scholars also continue to report varying results on the nutritional requirements of tilapia [8]. Conflicting results have appeared in the dietary lipid and protein requirements where different amounts have been recommended for improved growth and health of fish. Hitherto, little is known about additives, for example, enzymes, hormones, and pro/ prebiotics added into the tilapia diet with the aim to improve nutrient utilization and their interactions. Additionally, studies evaluating the results of supplementing with these additives often contrast with each other. For example, some studies $[9,10]$ assessing the influence of adding enzymes in fish diet reported great improvement in growth and nutrient digestibility, while others $[11,12]$ found zero to minimal effects. Maas et al. [13] pointed out that these differences may be due to differences between the supplied additives and the diet.

Previous reviews [14-17] have examined alternative sources of nutrients in the tilapia diets. However, most of these studies only focused on certain aspects of nutrition, and since they were done a couple of years back, they do not cover the new developments in dietary strategies that have occurred over the years. Therefore, the main objective of this review was to critically explore the dietary strategies that improve nutrient utilization in tilapia by assessing the strategies that have been employed for better utilization of aquafeeds and processing of feed ingredients and further debate their efficiencies. The review also tries to determine the extent to which studies on these dietary strategies have been conducted in tilapia nutrition and explores the major challenges and research gaps in this area. The significance of this review is that it will help to spot research gaps and propel in-depth research in the field. This review will also provide updated nutritional information for better utilization of aquafeeds and further help to identify research gaps and areas that need revalidation in this field to improve nutrient utilization in tilapia nutrition. Most research has been directed towards the nutrient requirements and feeding strategies of fish; hence, additional information is needed to better understand how efficient these dietary strategies are in terms of nutrient utilization by fish.

\section{Discussions}

\subsection{Strategies for Better Utilization of Aquafeeds}

2.1.1. Addition of Functional Feed Additives in Aquafeeds. The increase in tilapia farming has also resulted in an increased need for the development of improved feed formulations. Nutrients form part of the fish diet and are vital for regulating metabolism, maximizing the growth, reproduction, and health of the fish [18]. Over 40 of these nutrients are required by the fish with the need for each nutrient differing with age, weight, and body composition 
of the fish $[15,18,19]$. These nutrients are released during the food digestion process and can be grouped into macronutrients (proteins, lipids, and carbohydrates) and micronutrients (vitamins, minerals) depending on the amount required. It is important that these nutrients be provided in appropriate amounts so to optimize performance and efficiency [18]. Feed components are also often added in tilapia feed for better utilization of aquafeeds and to improve the physiological and economic significance of the culture. These components include enzymes, prebiotics, probiotics, hormones, feeding stimulants, and antioxidants.

The need for these additives stems from the increase in tilapia fish culture and the use of plant-based products aimed at meeting the demand for commercial diets. Some of these products, especially from plant origin, come with an increase in other antinutritional factors that can reduce the nutritional value of the feed. For example, 70\% phosphorus in plant food sources is available as a phytate which needs to be hydrolyzed with the enzyme phytase to release inorganic phosphorus, inositol, and other nutrients [20]. However, fish lack an intestinal phytase to hydrolize the phytate during digestion; hence, the phosphorus in their feed stuff is not readily available for them to efficiently utilize [20]. The presence of phytates in fish feed also reduces the availability of proteins and amino acids because they form protein complexes that are hard to digest [21]. Furthermore, the bioavailability of other minerals like copper, iron, zinc, calcium, magnesium, and manganese is reduced [22]. Previous studies have shown that supplementation of the diet with the enzyme phytase can be a solution. Phytase has been shown to improve protein digestion and the availability of minerals like phosphorus and calcium, as well as improve their utilization [23]. This helps in improving the feed quality and subsequently the tilapia fish growth. The efficiency of the enzyme phytase depends on the method of feed processing and the temperature should be less than $658^{\circ} \mathrm{C}$ [24]. Its efficiency is also dependent on its adaptation to fish physiology (Nwanna \& Schwarz, [25]).

Another enzyme has been employed to supplement tilapia feed in the protease enzyme which is used to improve nutrient utilization in low fishmeal diets. Fish meal is sometimes replaced with plant proteins in the diet, and this has been shown to significantly decrease the growth of fish and their feed digestibility and utilization [26]. It has also been shown that combining both phytase and protease enzymes further improves nutrient utilization and decreases the amount of inorganic phosphorus and fish meal needed in the diet compared to individual supplementation. Another issue with plant-derived feed sources is their low digestibility which results in low nutrient utilization and reduced growth in tilapia fish. The low digestibility of these plant products is as a result of the presence of the starch polysaccharide component within their structure [27]. The xylanase enzyme, which is a glycoside hydrolase produced by yeast, bacteria, and fungi, is therefore sometimes added into tilapia feed to improve the hydrolysis of these polysaccharides and hemicellulose of the cell walls of these plant-derived feed products [28]. In this way, the xylanase enzyme improves nutrient utilization of plant ingredients in food particularly carbohy- drates, hence aiding in fish growth. Efficient use of these plant materials also decreases the amount of feed needed, hence minimizing pollution to the aquatic environment. Other studies have also revealed that the xylanase enzyme improves fish performance by enhancing energy utilization $[10,29-32]$. However, the use of this xylanase enzyme for supplementation of feed in aquaculture is negatively affected by its high cost, hence the need for the development of more economically sustainable strategies.

[13] underlined that the influence of enzyme supplementation on the growth of fish and its nutrient digestibility is widely determined by the type of ingredients added in the feed. They incorporated ingredients containing different types of nonstarch polysaccharides (i.e., cellulose, hemicellulose, and pectin) which were wheat bran (WB), sunflower meal (SFM), and citrus pulp (CP) to a reference diet (REF), and the enzymes phytase and xylanase were added into the diet. The results indicated that enzyme supplementation in wheat bran and sunflower meal diets improved the growth rate of fish and the digestibility of ash, phosphorus, calcium, and nonstarch polysaccharides, whilst the performance of fish fed citrus pulp and reference diet did not improve. The enzyme supplementation also improved the feed conversion ratio (FCR) from 1.00 to 0.92 for the WB diet and from 1.12 to 1.07 for the SFM diet, whilst the FCR for the reference diet was low in nonstarch polysaccharides, and the pectin rich citrus pulp diet did not improve even with the enzyme supplementation. This shows that the efficiency of the enzymes in the fish diet depends on the ingredients used and in this case the nonstarch polysaccharide fraction composition. Different enzymes also target and hydrolyze different bonds; therefore, the digestibility of the feed also depends on the enzymes administered. The increased nutrient digestibility in turn results in enhanced fish growth. It is therefore important to know the composition of the diet and the targeted components before choosing the enzyme to supplement the diet to make sure that the enzyme supplementation is complementary with the diet composition [33]. The economic aspect should also be considered during enzyme supplementation to ensure profitability. Improved tilapia growth means extra income depending on the market prices.

The amount of enzyme added into the feed also widely influences their effectiveness in improving growth and feed utilization. For example, a study by Lin et al. [10] evaluated the influence of a combined solution of exogenous enzymes administered in different quantities in the diet on the growth performance of juvenile hybrid tilapia Oreochromis niloticus $\times$ Oreochromis. aureus. A commercial enzyme complex consisting of neutral protease, $\beta$-glucanase, and xylanase was added into the diet at the level of 0.0 (control group), 1.0, and $1.5 \mathrm{~g} \mathrm{~kg}^{-1}$ diet. The findings indicated that fish fed the basal diet with no enzymes exhibited lower growth than diet supplemented with enzymes. This indicates that the growth of tilapia fish greatly benefits from enzyme supplementation. Fish fed diets supplemented with exogenous enzymes also exhibited higher digestion of lipids, proteins, and gross energy compared to those fed the control diet. Nutrient digestibility was shown to improve with increase in the 
amount of supplemental enzyme added. These results suggest that the supplementation of fish diets with enzymes can compensate for the negative impacts of plant feed ingredients.

Nutritional supplements are slowly being used now in tilapia aquaculture to improve the health and gastrointestinal defense mechanisms of fish compared to antibiotics to which the fish can develop resistance to with time. Probiotics and prebiotics are one of the additives included in the tilapia diet to improve fish's resistance to diseases which can come due to opportunistic pathogens within the aquatic environment [34]. Prebiotic are nondigestible additives that improve the utilization of feed by encouraging the growth and activity of bacteria in the digestive tract that enhance fish health. Examples of these prebiotics include oligosaccharides, resistant starch, and specific nonstarch polysaccharides. Probiotics on the other hand are live microorganisms which when added to the fish diet enhancing the intestinal microbial balance [35]. Probiotics help in enhancing the zootechnical performance of tilapia fish, their immune response, and growth. The play of probiotics in aquaculture activities is also environmentally friendly and sustainable [34]. These probiotics can consist of microbes such as Bacillus sp., Pediococcus sp., Enterococcus sp. and Lactobacillus sp. One of the most commonly used probiotics in aquaculture is $B$. amyloliquefaciens, which has been shown in some studies to provide immunity and resistance against diseases such as $A$. hydrophila in Nile tilapia fish [36]. Prebiotics can also be used as an additive since they are resistant to attack by endogenous enzymes.

The use of probiotics in aquaculture is based on the concept of producing high-quality feed that maximizes growth and at the same time provides immunity [37]. It is also partly one of the attempts to produce functional and environmentally friendly aquafeeds. The impact of these probiotics on fish has been studied widely both from an individual supplement perspective and combined supplementation with other additives like enzymes. The addition of both probiotics and enzymes into the diet results in a complementary mode of action such as the production of fibre-degrading enzymes by probiotics which complements enzyme activity for digestion in fish [38]. Probiotics also produce digestive enzymes and stimulate the activity of some others like amylase, lipase, and protease, hence improving the digestibility of the feed [39]. Likewise, enzymes complement the action of probiotics by increasing the amount of available substrate for probiotics to work as well as encouraging the growth of beneficial bacteria [40].

Adeoye et al. [41] conducted a study to determine the combined effect of enzymes and the addition of probiotics on tilapia fish growth performance and health. This they did by conducting an experiment where tilapia were fed one of four diets, one of which was supplemented with enzymes (combination of phytase, xylanase, and protease) while the other probiotics (containing Bacillus subtilis, Bacillus licheniformis, and Bacillus pumilus), the third one a combination of the enzymes and probiotic, and the fourth one was the control. The results showed that fish fed the diet supplemented with a combination of probiotics and enzymes performed better in terms of final body weight (FBW), specific growth rate (SGR), protein efficiency ratio (PER), and feed conversion ratio (FCR). A 100\% survival was recorded in all treatments. This shows that supplementation of diet with a combination of probiotics and enzymes is capable of improving the growth and health status of tilapia fish. In addition, the enzymes also improve nutrient digestibility and enhance nutrient absorption and assimilation. However, in another study by Maas et al. [42], the synergistic effect expected from the addition of a combination of enzymes and probiotics in the diet was not observed. However, improved growth and FCR were still observed when these were applied individually. The microbial community in the gut of fish is also altered by the presence of probiotics, and the production of digestive enzymes (amylases, proteases, and lipases) also increases resulting in increased availability of nutrients such as short chain fatty acids and amino acids [39]. Probiotics (B. amyloliquefaciens) are also known to alter the gut environment through the changing of $\mathrm{pH}$, production of metabolites, and changing of physiology, which makes the environment less suitable for supplementing enzymes such as phytase and xylanase [43]. This reduces the digestion efficiency [42]. The effect of supplementation of diet with probiotics on fish performance differs from host to host and is also determined by strain differences, dose and duration of administration, culture environment, and diet composition.

Another important additive in aquafeeds is the inclusion of feeding stimulants which are meant to enhance palatability and feed acceptance [35]. These are mostly used when the fishes are very young, particularly at the larval stage where feed acceptability is of concern. Four important properties of these feeding stimulants need to be put into consideration, and these include components of low molecular weight, nitrogen has to be a constituent, they have to be nonvolatile and water soluble, and lastly, exhibit both acid and base properties (amphoteric) [44]. Compounds that can be used as stimulants include betaine and amino acids like glycine, alanine, or mixtures of L-amino acids and the nucleotides, inosine, or inosine 50-monophosphate. Organic acids are also good feeding stimulants for tilapia fish. Studies have also shown that carnivorous fish species positively respond to alkaline or nitrogenous stimulants such as valine, glycine, proline, betaine, and taurine, while herbivore species respond to acidic stimulants such as glutamic acid and aspartic acid [44].

Hormones are also an essential additive in tilapia aquafeeds where they are used to regulate a number of processes such as food intake, absorption, assimilation, metabolism, and excretion [45]. In this way, hormones influence the growth rate of the fish because all of these processes directly influence growth. Some of the most commonly used hormones include growth hormones, thyroid hormones, gonadotropins, prolactin, insulin, and steroids [35]. Despite their aforementioned importance in fish culture, the use of hormones is highly restricted due to consumer sensitivity concerns and government restrictions. Moreover, the overuse of some hormones like steroids can result in detrimental side effects such as early gonadal development, skeletal 
deformity, higher susceptibility to infections, and pathological changes in the liver, kidneys, and digestive tract [46].

Some fish feeds contain a high concentration of polyenoic fatty acids that are susceptible to oxidation and therefore need to be stabilized. Therefore, antioxidants can be added in the tilapia diet to minimize the deterioration and oxidative rancidity of the feed, thus preserving the fats and oils, vitamins, and other components of the feed [47]. The compounds that are produced during the rancidity process can also react with the epsilon amino group of lysine, hence further reducing the nutritional value of the diet. Prevention of lipid peroxidation with these antioxidants therefore helps keep the feed fresh. Antioxidants can either be natural (e.g., tocopherols, vitamin $\mathrm{C}$, and flavonoids), which are usually effective for a short period of time, or they can be synthetic (ethoxyquin, butylated hydroxytoluene, and butylated hydroxyanisole). Recent studies have shown that supplementing fish feed using a combination of lecithin and vitamin $C$ induces better growth rate, modifies fatty acids profile enhances fish physiological competence, and supports a potential antioxidant status [48]. Other synthetic antioxidants used in aquafeed include propyl gallate, ascorbyl palmitate, dilauryl thiodipropionate, and thiodipropionate [35].

\subsubsection{Feed Ingredient Processing Strategies for Improved} Nutritional Quality and Minimized Antinutritional Factors. The expansion of the aquaculture industry worldwide has also come with a coupled increase in the cost of aquafeed, which in turn has also led to the introduction of alternative strategies to replace traditional feed ingredients with cheaper unconventional ingredients [49]. However, these unconventional feed ingredients are limited because they contain high fibre and antinutritional factors [50]. The presence of antinutritional factors such as phytate can negatively affect the growth and feed efficiency due to poor nutrient digestibility in tilapia fish aquaculture [6]. Depending on the source of ingredients used to make the feed and the method used in processing them, antinutrients may have a significant impact on amino acid utilization, gut function, and immune response. Feed ingredient processing strategies aimed at improving nutritional quality and minimizing the impacts of these antinutritional factors to optimize the growth rates of tilapia fish are therefore necessary. Feed conversion ratio (FCR) is an important indicator of the quality of fish feed, with a lower FCR indicating better utilization of the feed. It is calculated by dividing the weight of the feed fed to the fish by the weight of fish growth. An FCR of less than 2 is generally considered to indicate good growth for most tilapia fish species [51].

Most fish culturing industries are aimed at promoting the growth, egg production, and health of fish at low costs, and therefore, the feed ingredient processes used are regarding these goals [52]. In the development of these strategies, a variety of factors need to be taken into consideration, such as the feed duration, frequency, ration size, and appetite of the fish being fed as well as their nutritional requirements. Feeding strategies also differ with the size of the fish, for example, smaller fish consume more feed in relation to body weight compared to larger fish. Feeding processing strategies are also dependent on the farming system being used, whether it is extensive, intensive, or semiextensive. When formulating fish diets, it is also necessary to know the dietary energy values of the ingredients and how much of each one of them should be incorporated into the feed [53]. The necessary additives that need to be incorporated into the feed to meet the nutrient requirements and achieve production goals at an optimal cost for tilapia species also need to be determined. Adding to these two, the impact that the processing strategies will have on the quality of the ingredients, their function, nutritional requirements of fish at different life stages, production systems, and market expectations need to be considered [53].

One feed ingredient processing strategy of significance in aquafeeds is fermentation which plays a big role in improving the nutritional quality of both animal- and plant-based protein sources. This process involves treating the source ingredients with microorganisms before adding them into the aquafeed [54]. In this way, the nutrients found in these sources are preserved, hence improving the nutritional value of the feed. Fermentation increases the vitamin content and protein solubility and reduces the crude fibre, antinutritional factors, and toxins found in the feed ingredients [55]. It also improves the palatability of the feed and digestibility of organic matter, fibres, and amino acids [56]. Fermented feed ingredients contain a lot of essential amino acids and biomolecules that are important for improving the growth performance of fish. Fermentation also breaks up carbohydrates into compounds of lower molecular weight, hence increasing the energy available and mineral absorption in fish [57]. Fermented dietary products tend to have higher water stability which improves feed ingestion in a short period of time [58]. Other roles played by fermented aquafeeds include improved disease resistance, inhibition of bacterial quorum sensing, immunity, stress tolerance, gut microbiota, and aquatic bioremediation. The most commonly used microorganisms in this fermentation process are fungal cells (Aspergillus sp.), yeast (Saccharomyces), and bacterial cells (Bacillus sp., Enterococcus sp., and Lactobacillus sp.) [59]. The two techniques used for fermentation are solid state fermentation and submerged fermentation method [60]. The former involves the addition of dry ingredients such as rice grains, rice bran, and wheat bran as well as the microorganism to be used in the formulation. Submerged fermentation, on the other hand, involves the suspension of the ingredients and growth of the microorganisms in an aqueous solution [61].

Dawood et al. [47] examined the influence of including fermented poultry by-product meal (FPBM) on the digestive enzyme activity and growth performance of Nile tilapia fish. This study used a diet made of fish meal and soybean meal as a control, and different levels of FPBM were added to create four other diets with 10,20,30, and 40\% FPBM. According to the results, the addition of FPBM at $11.17-25.14 \%$ improves the growth and health condition of tilapia fish. The fermented diet was shown to have an improved nutritional status in terms of having higher protein levels and essential amino acids compared to the untreated control 
diets. Another study by Hong et al. [62] evaluated the influence of fermentation with Aspergillus oryzae on the nutritional status of soybean meal. The nutrient content of fermented soybean meal was compared with that of raw soybean meal. The presence of antinutritional factors like trypsin inhibitor was also measured. Results revealed that the fermented soybean meal contained $10 \%$ more crude protein than raw soybean meal. Most of the trypsin inhibitor was eliminated from the fermented soybean meal, and the essential amino acid profile still remained the same after fermentation. From these studies, it is therefore evident that the fermentation process can help improve the quality of tilapia fish feed and its utilization, as well as remove the unwanted antinutritional factors in the diet.

Another technique used to eliminate or reduce the effects of antinutritional factors is heat treatment. This method is mostly used in the production of pelleted complete feeds to remove moisture and create a porous structure essential for subsequent oil absorption [63]. This improves the quality of the feed. Hot air drying of feed ingredients during processing helps inactivate most of the heat sensitive antinutritional factors. For example, a study by Peres et al. [64] indicated that autoclaving of soybean meal using the dry cycle at $130^{\circ} \mathrm{C}$ for 40 minutes improved the growth performance of fish and their feed utilization efficiency. However, care has to be taken to keep the heat minimal to avoid the destruction of essential amino acids such as methionine and lysine. Another study by Soltan [65] showed that soaking canola seed meal in water followed by heat treatment $\left(100^{\circ} \mathrm{C}\right.$ for $\left.40 \mathrm{~min}\right)$ reduced trypsin inhibitor, total polyphenolic compounds, and phytic acid by 80,69 , and $63 \%$, respectively. Ferreira et al. [66] evaluated the heat treatment of bean residue meal as an alternative protein source in diets for Nile tilapia fish. The study showed that the protein retention of the fish increases when bean residue meal is subjected to heat treatment. The findings from this study also revealed that the physical characteristics of the feed such as its durability, waterproof time, dry matter leaching, and water stability time are greatly improved. This is because heat gelatinizes the starch in the diet hence making the feed more stable [67]. From these studies, it is therefore evident that heat treatment can greatly improve the quality of the feed and reduce the impact of antinutritional factors in tilapia diets. These studies also show that appropriate levels of heat of heat can minimize the influence of nonstarch polysaccharides which prevent starch gelatinization in tilapia feed.

There are also a number of biological methods for removing antinutritional factors. Among these is the germination method which has been shown to significantly improve the nutritional value of fish feed by inducing the formation of enzymes that reduce phytates, trypsin inhibitors, and tannins in seeds and positively influence the proximate composition of the ingredients [68]. This method is sometimes used in combination with autoclaving, and the synergy of these two methods has been shown to be more effective in removing antinutritional factors in fish feed. Autoclaving involves moist heat treatment of the feed ingredients [69]. The combination of these methods can also increase the digestibility of dry matter and crude protein [70]. This increase in digestibility can be attributed to the changes in nutrient content of the ingredients, the destruction of antinutritional factors, and denaturing of nonnutritive complex molecules to simple nutritive ones from the feed ingredients such as the disruption of protein structures and cell wall encapsulated starch [71].

\subsubsection{Enhancing Feed Utilization through Genetic Selection} of Fish. As the demand for foods from aquatic sources continues to grow in response to human population growth and diminishing wild fish stocks, more possible feed products are being explored for sustainable management of the aquaculture industry. Some feed products, especially plant-based products, contain nutrients and antinutrients that are not ideal for aquafeeds, hence the need to change some specific traits through genetic manipulation. Genetic and genomic studies have looked at the molecular mechanisms that come to play in order for different traits to be expressed. Knowledge from these studies and the introduction of biotechnology and its development has allowed for the engineering of genetically modified fish and manipulation of genes in aquaculture aimed at improving valuables engineered to grow faster and have a lot of meat with less feed [72]. This not only boosts their market but also improves their feed conversion efficiency. The correlation of biochemical information with genetic data provides great insight into the functions of unknown genes and system responses to nutrient changes. It is important to know how fish that have been evolutionary selected to utilize most animal protein can thrive and be selected for improved utilization of plantbased products as their feed.

The most commonly used way of improving growth and enhancing feed conversion efficiency in fish to date is through the transfer of growth hormone gene constructs [73]. Growth hormone transgenic fish can mature to sizes larger than those in the wild and in a short period of time. Males also tend to grow larger due to their higher feed conversion efficiency compared to females. These phenotypic effects observed in fish also influence production characteristics (e.g., feed conversion efficiency, disease resistance, and growth rate) in turn. However, some of these fish species are prone to death after sexual maturity.

Improving feed efficiency in fish is of great importance at both economic and environmental levels. However, this goal has been hampered by the fact that only a limited number of studies have been conducted in an attempt to determine the influence of genotypes on nutrient utilization for tilapia species. Previous studies only related the growth performance, feed efficiency, digestibility, and proximate analysis of the fish to variation in diet composition. For an improved understanding of the role of genes in nutrient utilization among fish species, what is occurring to the fish not only physiologically with gene variation needs to be determined. In this way, nutritionists can then correlate dietary changes with specific physiological pathways and evaluate the diet according to proper nutritional needs differences. However, genetic modifications are not encouraged because of mutagenesis concerns 


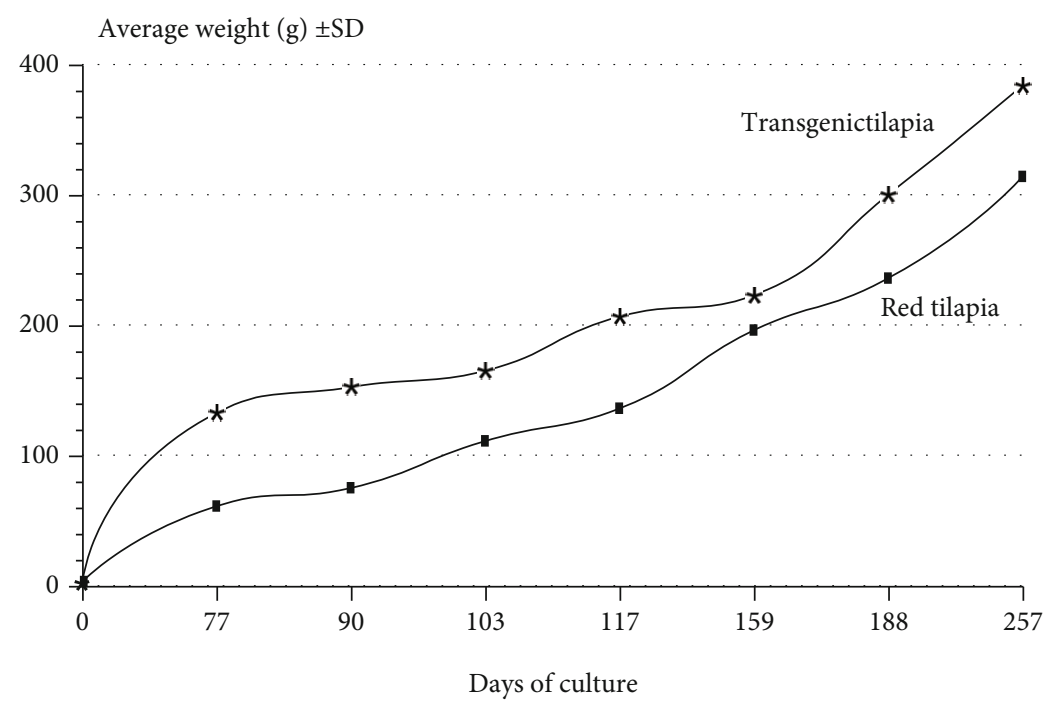

FIGURE 2: Average weight \pm SD increase in transgenic O. hornorum $\times$ O. aureus heterozygous tilapia compared to hybrid red tilapia under intensive polyculture conditions (Cabezas et al., [73]).

and the fear of undesirable side effects that can result from the integration and expression of recombinant genes [74]. Furthermore, predicting the ecological risk of transgenic fish escaping into the wild is difficult due to genotype by environment effects. Cabezas et al. [73] produced a transgenic hybrid tilapia (Oreochromis hornorum) by microinjection into early embryos of a transgene containing the tilapia growth hormone. They then cultured these transgenic tilapias in some conditions with nontransgenic tilapias. The results showed a better growth performance in transgenic fish than the nontransgenic red tilapia (Figure 2). These results confirm that genetic manipulations can improve the growth and feed utilization of fish.

2.1.4. Feed Types, Feed, and Feeding Strategies. The amount of feed to serve and how to serve it to the fish is determined by the prevailing conditions. The fish should be given just enough to support their nutritional needs and achieve optimal growth while minimizing feed wastage. The feed response is visually monitored and stopped when the fish reach satiation. The amount of protein in the feed, feeding rate, and frequency should be reduced as the fish grow. Another alternative to switching to a lower protein diet is maintaining the same protein level and reducing the amount of feed instead. Fish feed can either be complete, meaning it contains all necessary nutrients necessary to maximize the growth and health of the fish, or supplemental, meaning it contains only certain nutrients to complement already existing feed ingredients [75]. When fish are reared in indoor systems where they are confined and cannot forage freely on natural food, they must be provided a complete diet. In contrast, supplemental diets are intended only to help support the natural food normally available to fish in natural ecosystems. In most cases, farmers use complete diets which are composed of $28-50 \%$ protein [76, 77], 5-25\% lipids, 30 $45 \%$ starch [78-80], $<8.5 \%$ ash, $<1.5 \%$ phosphorus, $<10 \%$ water, and trace amounts of vitamins and minerals [15,
81]. The amount of all these nutrients also depends on the fish species and the life stage they are in.

Fish feed can either be live feed or artificial. Live feed is mostly found in natural ponds and includes phytoplankton and zooplanktons [82]. It is important for juvenile tilapias and helps to reduce the time taken for the organogenesis process and allows for early completion of a functional digestive system which subsequently optimizes the growth of the fry [5]. Juvenile Nile tilapia fish have been sown to display defects such as reduction in digestibility, absorption, and assimilation of nutrients when deprived access to live feed. This affects their overall growth performance throughout to the adulthood stage [83]. Organic and inorganic fertilizers are often used to boost the growth of phytoplankton in natural ponds as the main live food mostly consumed by juvenile tilapia. Artificial fish feed, on the other hand, can be divided into two types depending on whether it is manufactured as extruded or pressure-pelleted, the difference being that the latter is buoyant, while the former sinks. The extruded feeds are costly to manufacture; hence, they are expensive to buy. The feed type used in a culture depends on the fish species being cultured, but most species can be trained to accept floating feed. However, floating feed is advantageous because it is easier to observe how much the fish are eating and thus adjust the feeding rates accordingly. It is also easier to notice if your fish are not well because they constantly come to the surface to eat. A study by Workagegn et al. [84] revealed that fish fed different feed types also differ significantly in growth and feed utilization efficiency.

Appropriate feed management techniques are also large contributors to the appropriate utilization of feed by fish. Proper feeding management can reduce the feed cost to the extent of 15-20 percent by reducing waste [53]. Feeding the fishes rightly, according to their requirements is one of the biggest challenges in aquaculture. Both underfeeding and overfeeding are common. Underfeeding wastes feed leading to poor growth and low productivity while 
overfeeding should also be avoided to avoid water quality deterioration $[85,86]$. Most fish farmers in developing countries use manual feeding strategies such as broadcasting feed because they are less costly. However, several studies ([87-89]; Mohapatra et al., [90]) have also reported the use of automatic fish feeding devices which save time and labour compared to manual strategies.

2.2. Research Gaps and Formulation Challenges. From the literature review, it was noted that knowledge of dietary strategies that improve nutrient utilization remains incomplete and not well understood. Fish often exhibit unidentified growth factors which cannot be included when formulating the feed [91]. Restrictions and constraints are also unavoidable, for example, the inclusion of plant proteins in carnivorous fish diets is restricted to $15 \%$ or less to avoid molecules such as tannins, nonstarch polysaccharides, oligosaccharides, and mycotoxins reaching harmful levels that can impair the gut health and feed intake. Omnivorous fish on the other hand can accommodate up to 50\% plant material [27]. Other restrictions arise from the fact that the amino acid profile within the diet has to be balanced, and the nutrients should be digestible ones [15]. However, most of these nutrient sources especially proteins are costly which may limit the availability of feed processing and formulation technology to farmers. This often results in a trade-off between the feed cost and the nutritional value of the diet.

Additionally, ignorance of feed formulation and processing knowledge amongst farmers is a challenge. Most feed is formulated in laboratories and not under actual farming conditions and then sold to farmers who have no idea of the nutritional requirements of their farmed fish species [53]. This increases the risk of using inappropriate formulations among farmers. Inappropriate amounts of feed may be administered to fish or worse the wrong kind of feed meant for other fish species can be given out. The little research done on feed formulation and nutrient utilization is circulated among scientific researchers and not communicated to the farmers who actually need to employ these feeding strategies.

Most of the studies reviewed demonstrated that there is an interaction between the feeding strategies and the utilization of nutrients by the fish. Furthermore, a literature search has shown that although there has been a major shift in the use of plant feed materials, little has been done to overcome the challenges associated with the antinutritional factors they come with. For example, the efficiency of supplementing a feed with additives depends on the feed content and information on which additives to use for which the feed is not sufficiently and systematically covered. Additives such as enzymes are ideal to use under specific conditions like temperature and $\mathrm{pH}$; therefore, the lack of information on what enzyme to use in which culture conditions limits their cost-effectiveness. Thus, it is not surprising that there is disagreement among literatures on the dietary requirements and feeding strategies in tilapia nutrition. In addition, the nutritional requirements for tilapia fish are not fully understood.

Most literature only covers the nutritional needs of tilapia in general, yet different nutrients are required and uti- lized differently by tilapia of different ages, weight, and body composition. Information on nutritional requirements and utilization is also not linked properly to culture conditions, yet all this information is essential to optimize feed efficiency and subsequent growth performance of the fish. Studies have also shown that the genetic profile of the fish may also play a role in feed utilization. However, only a few studies have been conducted in this aspect, and many questions remain largely unanswered, and several research avenues remain open. Another challenge can stem from the variation of environmental conditions in different aquaculture systems, which also influences the response of the fish and its nutritional requirements. This makes the provision of species-specific feeds that meet the nutritional requirements of the fish at different life stages difficult. Future studies may include research on the use of feed processing strategies such as heat treatment is also vital. This is so to test the appropriate temperatures to use under different environmental conditions to inactivate different antinutritional factors. A holistic understanding of the influence of genes in nutrient utilization under different environmental conditions is therefore greatly needed. However, currently, most genetic manipulations are done in the laboratory, but not in actual culture conditions, so it is hard to make a simulation of the influence of genetic variation on nutrient utilization as it also varies with the culture conditions. Genetic experiments are also costly to conduct; hence, their use in improving nutrient utilization among fish is limited.

\section{Conclusions}

In conclusion, dietary sources for tilapia are slowly shifting to plant-based products. However, these come with a lot of antinutritional factors and digestibility problems; hence, the right feeding strategies have to be employed to enable efficient nutrient utilization. Nutritional requirements differ with culture stages; therefore, it is important to determine the nutritional requirements of the fish throughout their life cycle and subsequently employ appropriate feeding management strategies. It is recommended that feed formulation information be shared with farmers to ensure improved quality of feed and the use of appropriate feeding strategies in aquaculture at sustainable costs.

\section{Data Availability}

This study only reviews already published literature; no data was collected.

\section{Conflicts of Interest}

The authors declare that they have no conflicts of interest.

\section{Acknowledgments}

The authors would like to thank the Africa Center of Excellence for Water Management (ACEWM), Addis Ababa University, for logistics support. 


\section{References}

[1] A. E. Eknath and G. Hulata, "Use and exchange of genetic resources of Nile tilapia (Oreochromis niloticus)," Reviews in Aquaculture, vol. 1, no. 3-4, pp. 197-213, 2009.

[2] K. Fitzsimmons, "Future trends of tilapia aquaculture in the Americas," Tilapia aquaculture in the Americas, vol. 2, pp. 252-264, 2000.

[3] FAO (Food and Agriculture Organization), The State of World Fisheries and Aquaculture, FAO Fisheries and Aquaculture Department, Rome, 2020.

[4] R. Asmah, Development potential and financial viability of fish farming in Ghana, University of Stirling, 2008.

[5] A. G. Tacon and S. S. De Silva, "Feed preparation and feed management strategies within semi-intensive fish farming systems in the tropics," Aquaculture, vol. 151, no. 1-4, pp. 379404, 1997.

[6] A. G. Tacon and M. Metian, "Feed matter: satisfying the feed demand of aquaculture," Reviews in Fisheries Science \& Aquaculture, vol. 23, no. 1, pp. 1-10, 2015.

[7] W. K. Ng and N. Romano, "A review of the nutrition and feeding management of farmed tilapia throughout the culture cycle," Reviews in Aquaculture, vol. 5, no. 4, pp. 220254, 2013.

[8] M. Yan, X. Jiang, G. Wang et al., "Preparation of selfassembled collagen fibrillar gel from tilapia skin and its formation in the presence of acidic polysaccharides," Carbohydrate polymers, vol. 233, article 115831, 2020.

[9] M. R. Ghomi, R. Shahriari, H. F. Langroudi, M. Nikoo, and E. von Elert, "Effects of exogenous dietary enzymes on growth, body composition, and fatty acid profiles of cultured great sturgeon Huso huso fingerlings," Aquaculture International, vol. 20, no. 2, pp. 249-254, 2012.

[10] S. Lin, K. Mai, and B. Tan, "Effects of exogenous enzyme supplementation in diets on growth and feed utilization in tilapia, Oreochromis niloticus x O. aureus," Aquaculture research, vol. 38, no. 15, pp. 1645-1653, 2007.

[11] A. E. Ogunkoya, G. I. Page, M. A. Adewolu, and D. P. Bureau, "Dietary incorporation of soybean meal and exogenous enzyme cocktail can affect the physical characteristics of faecal material egested by rainbow trout (Oncorhynchus mykiss)," Aquaculture, vol. 254, no. 1-4, pp. 466-475, 2006.

[12] N. O. Yigit and M. Olmez, "Effects of cellulase addition to canola meal in tilapia (Oreochromis niloticus L.) diets," Aquaculture Nutrition, vol. 17, no. 2, pp. e494-e500, 2011.

[13] R. M. Maas, M. C. Verdegem, and J. W. Schrama, "Effect of non-starch polysaccharide composition and enzyme supplementation on growth performance and nutrient digestibility in Nile tilapia (Oreochromis niloticus)," Aquaculture Nutrition, vol. 25, no. 3, pp. 622-632, 2019.

[14] A. F. M. El-Sayed, "Alternative dietary protein sources for farmed tilapia, Oreochromis spp.," Aquaculture, vol. 179, no. 1-4, pp. 149-168, 1999.

[15] K. Jauncey, "Nutritional requirements," in Tilapias: Biology and Exploitation, pp. 327-375, Springer, Dordrecht, 2000.

[16] C. Lim, E. Li, and P. H. Klesius, "Distiller's dried grains with solubles as an alternative protein source in diets of tilapia," Reviews in Aquaculture, vol. 3, no. 4, pp. 172-178, 2011.

[17] S. Y. Shiau, Tilapia, Oreochromis spp. nutrient requirements and feeding of finfish for aquaculture, CAB International, Wallingford, 2002.
[18] S. P. Lall and A. Dumas, "Nutritional requirements of cultured fish: formulating nutritionally adequate feeds," in Feed and Feeding Practices in Aquaculture, pp. 53-109, Woodhead publishing, 2015.

[19] C. B. Cowey and C. Y. Cho, "Nutritional requirements of fish," Proceedings of the Nutrition Society, vol. 52, no. 3, pp. 417-426, 1993.

[20] W. Eeckhout and M. De Paepe, “Total phosphorus, phytate phosphorus and phytase activity in plant feedstuffs," Animal Feed Science and Technology, vol. 47, no. 1-2, pp. 19-29, 1994.

[21] M. Sajjadi and C. G. Carter, "Effect of phytic acid and phytase on feed intake, growth, digestibility, and trypsin activity in Atlantic salmon (Salmo salar)," Aquaculture Nutrition, vol. 10, no. 2, pp. 135-142, 2004.

[22] E. Papatryphon, R. A. Howell, and J. H. Soares Jr., "Growth and mineral absorption by striped bass Morone saxatilis fed a plant feedstuff based diet supplemented with phytase," Journal of the World Aquaculture Society, vol. 30, no. 2, pp. 161-173, 1999.

[23] Z. J. Cheng and R. W. Hardy, "Effects of microbial phytase supplementation in corn distiller's dried grain with solubles on nutrient digestibility and growth performance of rainbow trout, Oncorhynchus mykiss," Journal of Applied Aquaculture, vol. 15, no. 3-4, pp. 83-100, 2004.

[24] Y. Luo, Y. Su, R. Z. Lin, H. H. Shi, and X. R. Wang, "2-Chlorophenol induced ROS generation in fish Carassius auratus based on the EPR method," Chemosphere, vol. 65, no. 6, pp. 1064-1073, 2006.

[25] L. C. Nwanna and F. J. Schwarz, "Effect of phytase on the availability of phosphorus for common carp (Cyprinus carpio)," in Conference on Fish Nutrition Basics and Towards Sustainability. XII Internat. Symp. on Fish Nutrition and Feeding, Biarritz, France, 2006.

[26] Z. Shi, X. Q. Li, M. K. Chowdhury, J. N. Chen, and X. J. Leng, "Effects of protease supplementation in low fish meal pelleted and extruded diets on growth, nutrient retention, and digestibility of gibel carp, Carassius auratus gibelio," Aquaculture, vol. 460, pp. 37-44, 2016.

[27] G. Francis, H. P. Makkar, and K. Becker, "Antinutritional factors present in plant-derived alternative fish feed ingredients and their effects in fish," Aquaculture, vol. 199, no. 3-4, pp. 197-227, 2001.

[28] M. S. Hassaan, E. Y. Mohammady, M. R. Soaudy, and A. A. Abdel Rahman, "Exogenous xylanase improves growth, protein digestibility and digestive enzymes activities in Nile tilapia, Oreochromis niloticus, fed different ratios of fish meal to sunflower meal," Aquaculture Nutrition, vol. 25, no. 4, pp. 841-853, 2019.

[29] Q. Ai, K. Mai, W. Zhang et al., "Effects of exogenous enzymes (phytase, non-starch polysaccharide enzyme) in diets on growth, feed utilization, nitrogen and phosphorus excretion of Japanese seabass, Lateolabrax japonicus," Comparative Biochemistry and Physiology Part A: Molecular \& Integrative Physiology, vol. 147, no. 2, pp. 502-508, 2007.

[30] T. O. O. Babalola, "The effects of feeding Moina, microdiet and xylanase supplemented microdiet on growth and survival of Clarias gariepinus (Burchell) larvae," Nigerian Journal of Fisheries, vol. 2, pp. 205-217, 2006.

[31] S. N. Hlophe-Ginindza, N. A. Moyo, J. W. Ngambi, and I. Ncube, "The effect of exogenous enzyme supplementation on growth performance and digestive enzyme activities in 
Oreochromis mossambicus fed kikuyu-based diets," Aquaculture Research, vol. 47, no. 12, pp. 3777-3787, 2016.

[32] T. T. Jiang, L. Feng, Y. Liu et al., "Effects of exogenous xylanase supplementation in plant protein-enriched diets on growth performance, intestinal enzyme activities, and microflora of juvenile Jian carp," Aquaculture Nutrition, vol. 20, no. 6, pp. 632-645, 2014.

[33] D. I. Officer, "Feed enzymes," Farm animal metabolism and nutrition, vol. 19, pp. 405-426, 2000.

[34] T. L. Welker and C. Lim, "Use of probiotics in diets of tilapia," Aquaculture Research \& Development, vol. 1, no. 14, 2011.

[35] T. A. Alemayehu, A. Geremew, and A. Getahun, "The role of functional feed additives in tilapia nutrition," Fisheries and Aquaculture Journal, vol. 9, no. 2, 2018.

[36] R. B. Cavalcante, G. S. Telli, L. Tachibana et al., "Probiotics, prebiotics, and synbiotics for Nile tilapia: growth performance and protection against Aeromonas hydrophila infection," Aquaculture Reports, vol. 17, article 100343, 2020.

[37] V. Kiron, "Fish immune system and its nutritional modulation for preventive health care," Animal Feed Science and Technology, vol. 173, no. 1-2, pp. 111-133, 2012.

[38] A. K. Ray, K. Ghosh, and E. J. A. N. Ring $\varnothing$, "Enzyme-producing bacteria isolated from fish gut: a review," Aquaculture Nutrition, vol. 18, no. 5, pp. 465-492, 2012.

[39] F. K. Kuebutornye, E. D. Abarike, M. E. Sakyi, Y. Lu, and Z. Wang, "Modulation of nutrient utilization, growth, and immunity of Nile tilapia, Oreochromis niloticus: the role of probiotics," Aquaculture International, vol. 28, no. 1, pp. 277-291, 2020.

[40] M. Bedford and A. J. Cowieson, "Exogenous enzymes and their effects on intestinal microbiology," Animal Feed Science and Technology, vol. 173, no. 1-2, pp. 76-85, 2012.

[41] A. A. Adeoye, R. Yomla, A. Jaramillo-Torres, A. Rodiles, D. L. Merrifield, and S. J. Davies, "Combined effects of exogenous enzymes and probiotic on Nile tilapia (Oreochromis niloticus) growth, intestinal morphology and microbiome," Aquaculture, vol. 463, pp. 61-70, 2016.

[42] R. M. Maas, M. C. Verdegem, S. Debnath, L. Marchal, and J. W. Schrama, "Effect of enzymes (phytase and xylanase), probiotics (B. amyloliquefaciens), and their combination on growth performance and nutrient utilisation in Nile tilapia," Aquaculture, vol. 533, article 736226, 2021.

[43] M. A. Dawood, S. Koshio, M. M. Abdel-Daim, and H. Van Doan, "Probiotic application for sustainable aquaculture," Reviews in Aquaculture, vol. 11, no. 3, pp. 907-924, 2019.

[44] C. E. Carr, L. Maler, and E. Sas, "Peripheral organization and central projections of the electrosensory nerves in gymnotiform fish," Journal of Comparative Neurology, vol. 211, no. 2, pp. 139-153, 1982.

[45] A. J. Matty, "Nutrition, hormones and growth," Fish physiology and biochemistry, vol. 2, no. 1-4, pp. 141-150, 1986.

[46] A. L. Gannam and R. T. Lovell, "Growth and bone development in channel catfish fed 17- $\alpha$-methyltestosterone in production ponds," Journal of the World Aquaculture Society, vol. 22, no. 2, pp. 95-100, 1991.

[47] M. A. Dawood, F. I. Magouz, M. Mansour et al., "Evaluation of yeast fermented poultry by-product meal in Nile Tilapia (Oreochromis niloticus) feed: effects on growth performance, digestive enzyme activity, innate immunity, and antioxidant capacity," Frontiers in veterinary science, vol. 6, p. 516, 2020.
[48] N. E. Saleh, E. A. Wassef, M. A. Kamel, E. R. El-Haroun, and R. A. El-Tahan, "Beneficial effects of soybean lecithin and vitamin C combination in fingerlings gilthead seabream (Sparus aurata) diets on; fish performance, oxidation status and genes expression responses," Aquaculture, vol. 546, article 737345, 2022.

[49] M. S. Hossain, S. Koshio, M. Ishikawa et al., "Efficacy of nucleotide related products on growth, blood chemistry, oxidative stress, and growth factor gene expression of juvenile Red sea bream, Pagrus major," Aquaculture, vol. 464, pp. 8-16, 2016.

[50] X. Y. Bu, Y. Y. Wang, F. Y. Chen et al., "An Evaluation of replacing fishmeal with rapeseed meal in the diet of Pseudobagrus ussuriensis: growth, feed utilization, nonspecific immunity, and growth-related gene expression," Journal of the World Aquaculture Society, vol. 49, no. 6, pp. 1068-1080, 2018.

[51] S. Craig, L. A. Helfrich, D. Kuhn, and M. H. Schwarz, Understanding fish nutrition, feed, and feeding, Virginia State University, 2017.

[52] R. L. Naylor, R. W. Hardy, D. P. Bureau et al., "Feeding aquaculture in an era of finite resources," Proceedings of the National Academy of Sciences, vol. 106, no. 36, pp. 1510315110, 2009.

[53] J. M. Munguti, S. Musa, P. S. Orina et al., An overview of the current status of Kenyan fish feed industry and feed management practices, challenges, and opportunities, Maseno University, 2014.

[54] M. A. Siddik, J. Howieson, I. Ilham, and R. Fotedar, "Growth, biochemical response, and liver health of juvenile barramundi (Lates calcarifer) fed fermented and non-fermented tuna hydrolysate as fishmeal protein replacement ingredients," PeerJ, vol. 6, article e4870, 2018.

[55] E. W. Mwihia, P. G. Mbuthia, G. S. Eriksen et al., "Occurrence and levels of aflatoxins in fish feeds and their potential effects on fish in Nyeri, Kenya," Toxins, vol. 10, no. 12, p. 543, 2018.

[56] M. S. Hassaan, M. A. Soltan, E. Y. Mohammady, M. A. Elashry, E. R. El-Haroun, and S. J. Davies, "Growth and physiological responses of Nile tilapia, Oreochromis niloticus fed dietary fermented sunflower meal inoculated with Saccharomyces cerevisiae and Bacillus subtilis," Aquaculture, vol. 495, pp. 592-601, 2018.

[57] I. Ilham and R. Fotedar, "Growth, enzymatic glutathione peroxidase activity and biochemical status of juvenile barramundi (Lates calcarifer) fed dietary fermented soybean meal and organic selenium," Fish physiology and biochemistry, vol. 43, no. 3, pp. 775-790, 2017.

[58] O. Fagbenro, K. Jauncey, and G. Haylor, "Nutritive value of diet containing dried lactic acid, fermented fish silage, and soybean meal for juvenile Oreochromis niloticus and Clarias gariepinus," Aquatic Living Resources, vol. 7, no. 2, pp. 79-85, 1994.

[59] A. Mukherjee, D. Dutta, S. Banerjee et al., "Potential probiotics from Indian major carp, Cirrhinus mrigala. Characterization, pathogen inhibitory activity, partial characterization of bacteriocin, and production of exoenzymes," Research in veterinary science, vol. 108, pp. 76-84, 2016.

[60] R. Subramaniyam and R. Vimala, "Solid state and submerged fermentation for the production of bioactive substances: a comparative study," International Journal of Natural Sciences, vol. 3, no. 3, pp. 480-486, 2012.

[61] Y. H. Shim, P. L. Shinde, J. Y. Choi et al., "Evaluation of multimicrobial probiotics produced by submerged liquid and solid substrate fermentation methods in broilers," Asian- 
Australasian Journal of Animal Sciences, vol. 23, no. 4, pp. 521-529, 2010.

[62] K. J. Hong, C. H. Lee, and S. W. Kim, “Aspergillus oryzae GB107 fermentation improves the nutritional quality of food soybeans and feed soybean meals," Journal of medicinal food, vol. 7, no. 4, pp. 430-435, 2004.

[63] M. Sørensen, "A review of the effects of ingredient composition and processing conditions on the physical quality of extruded high-energy fish feed as measured by prevailing methods," Aquaculture nutrition, vol. 18, no. 3, pp. 233-248, 2012.

[64] H. Peres, C. Lim, and P. H. Klesius, "Nutritional value of heattreated soybean meal for channel catfish (Ictalurus punctatus)," Aquaculture, vol. 225, no. 1-4, pp. 67-82, 2003.

[65] M. A. Soltan, "Potential of using raw and processed canola seed meal as an alternative fish meal protein source in diets for Nile tilapia (Oreochromis niloticus)," Egyptian Journal of Nutrition and Feeds, vol. 8, no. 1, pp. 1111-1128, 2005.

[66] M. L. S. Ferreira, F. M. da Silva, M. C. Dos Santos, J. E. C. Lucena, R. Y. Sado, and Á. J. de Almeida Bicudo, "Heat-treated bean (Phaseolus vulgaris) residue meal as an alternative protein source in pelleted diets for Nile tilapia fingerlings: growth, body composition, and physical characteristics of diet," Tropical animal health and production, vol. 52, no. 5, pp. 24432450, 2020.

[67] K. Hua and D. P. Bureau, "A mathematical model to explain variations in estimates of starch digestibility and predict the digestible starch content of salmonid fish feed," Aquaculture, vol. 294, no. 3-4, pp. 282-287, 2009.

[68] A. H. Khalil and E. H. Mansour, "The effect of cooking, autoclaving, and germination on the nutritional quality of faba beans," Food Chemistry, vol. 54, no. 2, pp. 177-182, 1995.

[69] P. Siddhuraju and K. Becker, "Nutritional and antinutritional composition, in vitro amino acid availability, starch digestibility, and predicted glycemic index of differentially processed mucuna beans (Mucuna pruriens): under-utilised legume," Food chemistry, vol. 91, no. 2, pp. 275-286, 2005.

[70] A. E. Mubarak, "Nutritional composition and antinutritional factors of mung bean seeds (Phaseolus aureus) as affected by some home traditional processes," Food chemistry, vol. 89, no. 4, pp. 489-495, 2005.

[71] L. E. Cruz-Suarez, D. Ricque-Marie, M. Tapia-Salazar, I. M. McCallum, and D. Hickling, "Assessment of differently processed fed pea (Pisum sativum) meals and canola meal (Brassica sp.) in diets for blue shrimp (Litopenaeus stylirostris)," Aquaculture, vol. 196, no. 1-2, pp. 87-104, 2001.

[72] Y. K. Nam, J. K. Noh, Y. S. Cho et al., "Dramatically accelerated growth and extraordinary gigantism of transgenic mud loach Misgurnus mizolepis," Transgenic research, vol. 10, no. 4, pp. 353-362, 2001.

[73] L. Cabezas, F. Herrera, R. Martinez, A. Arenal, M. P. Estrada, and J. de la Fuente, "Growth performance of transgenic hybrid tilapia (Oreochromis spp.) under intensive culture conditions," in Proceedings of the Fourth International Symposium on Tilapia in Aquaculture, vol. 1, pp. 109-115, Havana Cuba, 1997.

[74] F. Forabosco, M. Löhmus, L. Rydhmer, and L. F. Sundström, "Genetically modified farm animals and fish in agriculture: a review," Livestock Science, vol. 153, no. 1-3, pp. 1-9, 2013.

[75] J. S. Diana, Feeding strategies. In Dynamics of pond aquaculture, CRC press, 2017.

[76] A. F. M. El-Sayed and M. Kawanna, "Effects of dietary protein and energy levels on spawning performance of Nile tilapia
(Oreochromis niloticus) broodstock in a recycling system," Aquaculture, vol. 280, no. 1-4, pp. 179-184, 2008.

[77] L. Ning, Y. Liu, W. Wang, Y. Li, L. Chen, and Z. Y. Du, "The metabolic regulation of fenofibrate depends on dietary protein content in male juveniles of Nile tilapia (Oreochromis niloticus)," British Journal of Nutrition, vol. 122, no. 6, pp. 648-656, 2019.

[78] S. Boonanuntanasarn, A. Jangprai, S. Kumkhong et al., "Adaptation of Nile tilapia (Oreochromis niloticus) to different levels of dietary carbohydrates: New insights from a long term nutritional study," Aquaculture, vol. 496, pp. 58-65, 2018.

[79] L. Y. Li, Y. Wang, S. M. Limbu et al., "Reduced fatty acid $\beta$-oxidation improves glucose catabolism and liver health in Nile tilapia (Oreochromis niloticus) juveniles fed a high-starch diet," Aquaculture, vol. 535, article 736392, 2021.

[80] Y. Wang, Y. J. Liu, L. X. Tian et al., "Effects of dietary carbohydrate level on growth and body composition of juvenile tilapia, Oreochromis niloticus $\times$ O. aureus," Aquaculture research, vol. 36, no. 14, pp. 1408-1413, 2005.

[81] A. Y. He, L. J. Ning, L. Q. Chen et al., "Systemic adaptation of lipid metabolism in response to low-and high-fat diet in Nile tilapia (Oreochromis niloticus)," Physiological Reports, vol. 3, no. 8, article e12485, 2015.

[82] A. D. Evangelista, N. R. Fortes, and C. B. Santiago, "Comparison of some live organisms and artificial diet as feed for Asian catfish Clarias macrocephalus (Günther) larvae," Journal of applied Ichthyology, vol. 21, no. 5, pp. 437-443, 2005.

[83] C. D. Bishop, R. A. Angus, and S. A. Watts, "The use of feather meal as a replacement for fish meal in the diet of Oreochromis niloticus fry," Bioresource Technology, vol. 54, no. 3, pp. 291295, 1995.

[84] K. B. Workagegn, E. D. Ababboa, G. T. Yimer, and T. A. Amare, "Growth performance of the Nile tilapia (Oreochromis niloticus L.) fed different types of diets formulated from varieties of feed ingredients," Journal of Aquaculture Research \& Development, vol. 5, no. 3, p. 1, 2014.

[85] O. Emmanuel, A. Chinenye, F. Gbadebo, O. Richardson, and K. Peter, "Development of an automatic fish feeder. International Institute of Tropical Agriculture Postharvest Unit," Ibadan-African Journal of Root and Tuber Crop, vol. 10, no. 1, pp. 27-32, 2013.

[86] J. V. Lee, J. L. Loo, Y. D. Chuah, P. Y. Tang, Y. C. Tan, and W. J. Goh, "The use of vision in a sustainable aquaculture feeding system," Research Journal of Applied Sciences, Engineering and Technology, vol. 6, no. 19, pp. 3658-3669, 2013.

[87] W. J. Baldwin, "The design and operation of an automatic feed dispenser," Aquaculture, vol. 34, no. 1-2, pp. 151-155, 1983.

[88] N. Charlon and P. Bergot, "An improved automatic dry food dispenser for fish larvae," The Progressive Fish-Culturist, vol. 48, no. 2, pp. 156-158, 1986.

[89] N. C. Parker, “Technical notes: low-cost automated feeder for fry and fingerlings," The Progressive Fish-Culturist, vol. 51, no. 1, pp. 42-46, 1989.

[90] B. C. Mohapatra, B. Sarkar, and S. K. Singh, "Use of plastics in aquaculture," in Plasticulture intervention for agriculture development in North Eastern Region. ICAR Research Complex for NEH Region, pp. 290-305, Umiam, Meghalaya, 2003.

[91] J. W. Hertrampf and F. Piedad-Pascual, Handbook on Ingredients for Aquaculture Feeds, Springer Science \& Business Media, 2012 . 